\title{
System reliability models for bridge structures
}

\author{
A. S. NOWAK* \\ University of Nebraska, Lincoln, NE 68588-0531, USA
}

\begin{abstract}
There is a growing need for a more accurate assessment of the load carrying capacity of highway bridges. The traditional approach is based on consideration of individual components rather than structures. Consequently, the acceptance criteria are formulated in terms of the allowable stress, or ultimate moment, in a component. However, it has been observed that the load carrying capacity of the whole structure (system) is often much larger than what is determined by the design of components. The difference can be attributed to the system behaviour. Quantification of this difference is the subject of the system reliability. There is a need to take advantage of the available system reliability methods and advanced structural analysis methods and apply them in the design of bridges and evaluation of existing structures. The current advanced analytical procedures allow for a numerically accurate but deterministic analysis of strain/stress in a bridge. Mathematical procedures exist for the calculation of reliability for various idealized systems: parallel, series, and combinations. There are also new developments in materials, technology, and field testing which can be used to improve bridge design and evaluation. This paper deals with calculation of the reliability of the whole bridge structure, taking into account realistic boundary conditions, and site-specific load and resistance parameters.
\end{abstract}

Keywords: system reliability models, bridge structures.

\section{Introduction}

The owners of highway bridges are often faced with a serious problem. A considerable percentage of structures are in a questionable condition while there are limited resources for repairs and replacements. The major factors that have contributed to the present situation are: the age, inadequate maintenance, increasing load spectra and environmental contamination [1]. The deficient bridges are posted, repaired or replaced. The disposition of bridges involves clear economical and safety implications. To avoid high costs of replacement or repair, the evaluation must accurately reveal the present load carrying capacity of the structure and predict loads and any further changes in the capacity (deterioration) in the applicable time span. The traditional component-based approach often does not allow to reveal the actual load carrying capacity. Therefore, system reliability can be used as an important tool in the efficient evaluation of existing structures.

The accuracy of bridge evaluation can be improved by using the recent developments in bridge diagnostics, structural tests and material tests. Advanced diagnostic procedures can be applied to the evaluation of the current capacity of the structure, monitoring of load and resistance history and evaluation of the accumulated damage. Full scale bridge tests can provide very useful information about the structural behaviour. For example, recent proof load tests confirmed that the load carrying capacity of girder bridges is larger then analytically predicted $[2,3]$, due to unintended composite action, partial fixity of supports (frozen bearings), and the contribution of sidewalks, parapets and railings. There is a need for significantly more test data, covering various bridge types. Recent developments in the area of materials allow for a better understanding of the behaviour of bridge com-

* e-mail: anowak2@unl.edu ponents. The availability of new materials may improve bridge repair techniques. More data is now available on bridge loads, static and dynamic. Available diagnostic technologies, including state of the art digital signal processes, integrated sensor systems, and microwave, acoustic and optical techniques, can be applied in bridge evaluation. However, extensive test programs are very costly. Therefore, a considerable effort should be directed towards evaluation and improvement of the current analytical methods, on the basis of available test data [4].

Computer methods of structural analysis have improved the accuracy of representing the actual behaviour of bridge components. Advanced programs (e.g. ABAQUS, NASTRAN, ANSYS) are available for linear and nonlinear analysis of complex structural systems. A dense element mesh allows for an accurate determination of strain/stress at almost any point in the structure. One major problem that remains is how to represent boundary conditions and material properties. For example, the actual support insitu is often different than an idealized type, and strength of material and modulus of elasticity can be different than what is assumed in design. The deterministic analysis is a useful tool, but there is need to include the randomness of parameters such as these.

Load and resistance parameters are random variables. Therefore, the probability of failure can be considered as a rational measure of structural performance. New advances that are significant for bridge evaluation have taken place in the area of probabilistic methods. There are procedures available for calculation of the probability of failure for given limit state function and statistical parameters of basic variables. There are simple closed formed solutions, iterative methods, and simulations. The advanced methods provide accurate results. In bridge engineering, the probabilistic methods were mostly applied in the development of a new generation of design codes 
(AASHTO LRFD 2004; CHBDC 2003: Eurocodes) [5-7]. However, they were dealing with ultimate limit states for individual components rather than systems.

Furthermore, secondary elements such as barriers, sidewalks, and diaphragms may increase the load carrying capacity of girder bridges. This in turn affects reliability. The potential benefit of secondary elements on the system reliability of girder bridges was considered by Eamon and Nowak in [8]. Simple span, two lane structures were considered, with composite steel girders supporting a reinforced concrete deck. For structural analysis, a finite element procedure was developed that combines a grillage model of the bridge deck with solid elements for edge-stiffening effects. It was found that the interaction of typical secondary element combinations has a varying effect on system reliability, depending on element stiffness, bridge span, and girder spacing.

The objective of this paper is to compare the reliability of components and whole system for girder bridges. The reliability analysis is performed for main girders, secondary elements, and sensitivity analysis is performed for load and resistance parameters. The mathematical idealization is a function of geometry and material properties. The obtained system reliability models can be applied to develop more rational bridge design and evaluation procedures.

The obtained reliabilities are compared with the target values, selected by considering consequences of failure and incremental (marginal) cost of safety. The target reliability can be different for primary and secondary components, single load path and multiple load path components, and further depend on the time interval between inspections [9]. In the paper the focus is on the differences between the reliabilities calculated for components and structural systems.

\section{Limit states}

The available reliability methods are presented in several books [10]. Reliability analysis can be performed using iterative procedures, by Monte Carlo simulations or using special sampling techniques. Limit states are the boundaries between safety and failure. In bridge structures failure can be defined as inability to carry traffic. Bridges can fail in many ways (modes of failure), by cracking, corrosion, excessive deformations, exceeding carrying capacity for shear or bending moment, local or overall buckling, and so on. Members can fail in a ductile or brittle manner. In the traditional approach, each mode of failure is considered separately.

There are three types of limit states. Ultimate limit states (ULS) are mostly related to the bending capacity, shear capacity and stability. Serviceability limit states (SLS) are related to gradual deterioration, user's comfort or maintenance costs. For example, in prestressed concrete girders, a crack opening under heavy live load is not a problem in itself. However, a repeated crack opening may allow penetration of moisture and corrosion of the prestressing steel. The serviceability limit states such as cracking, deflection or vibration, often govern the bridge design. The critical factors are both magnitude and frequency of load. Other serviceability limit states, vibrations or deflections, are related to bridge user's comfort rather than structural integrity. The third type of limit state is fatigue. The main concern is accumulation of damage caused by repeated applications of load (trucks). Therefore, the model must also include the load magnitude and frequency of occurrence, rather than just load magnitude as is the case in the ultimate limit states. This paper is focused on the ultimate limit state of the moment carrying capacity.

\section{Reliability index}

A traditional notion of the safety limit is associated with the ultimate limit states. For example, a beam fails if the moment due to loads exceeds the moment carrying capacity. Let $R$ represent the resistance (moment carrying capacity) and $Q$ represent the load effect (total moment applied to the considered beam). Then the corresponding limit state function, $g$, can be written,

$$
g=R-Q .
$$

If $g>0$, the structure is safe, otherwise it fails. The probability of failure, $P_{F}$, is equal to,

$$
P_{F}=\operatorname{Prob}(R-Q<0)=\operatorname{Prob}(g<0) .
$$

Let the probability density function (PDF) of $R$ be $f_{R}$ and PDF of $Q$ be $f_{Q}$. Then, let $Z=R-Q$. $Z$ is also a random variable and it represents the safety margin.

In general, the limit state function can be a function of many variables (load components, influence factors, resistance parameters, material properties, dimensions, analysis factors). A direct calculation of $P_{F}$ may be very difficult, if not impossible. Therefore, it is convenient to measure structural safety in terms of a reliability index, $\beta$. Reliability index is directly related to the probability of failure:

$$
\beta=-\Phi^{-1}\left(P_{F}\right)
$$

where $\Phi^{-1}=$ inverse standard normal distribution function. There are various procedures available for calculation of $\beta$. These procedures vary with regard to accuracy, required input data and computing costs and they are described in [10]. The simplest case involves the linear limit state function, Eq. 1.

If both $R$ and $Q$ are independent (in the statistical sense), normal random variables, then the reliability index is,

$$
\beta=\left(m_{R}-m_{Q}\right) /\left(\sigma_{R}^{2}+\sigma_{Q}^{2}\right)^{1 / 2}
$$

where $m_{R}=$ mean of $R, m_{Q}=$ mean of $Q, \sigma_{R}=$ standard deviation of $R$ and $\sigma_{Q}=$ standard deviation of $Q$.

If both $R$ and $Q$ are lognormal random variables, then $\beta$ can be approximated by

$$
\beta=(\ln R-\ln Q) /\left(\sigma_{\ln R}^{2}+\sigma_{\ln Q}^{2}\right)^{1 / 2}
$$


where $\ln R=\ln m_{R}-0.5 \sigma_{\ln R}^{2} \approx \ln m_{R}$ for $V_{R}<0.20$; $\ln Q=\ln m_{Q}-0.5 \sigma_{\ln Q}^{2} \approx \ln m_{Q}$ for $V_{Q}<0.20 ; \sigma_{\ln R}^{2}=$ $\ln \left[V_{R}^{2}+1\right] \approx V_{R}^{2}$ for $V_{R}<0.20 ; \sigma_{\ln Q}^{2}=\ln \left[V_{Q}^{2}+1\right] \approx V_{Q}^{2}$ for $V_{Q}<0.20 ; V_{R}=$ coefficient of variation of $R ; V_{Q}=$ coefficient of variation of $Q$.

The previous two equations require the knowledge of only two parameters for each random variable, the mean and standard deviation (or coefficient of variation). Therefore, the formulas belong to the second moment methods. If the parameters $R$ and $Q$ are not both normal or both lognormal, then the formulas give only an approximate value of $\beta$. In such a case, the reliability index can be calculated using the iterative procedure, sampling techniques, or by Monte Carlo simulations [10].

Rackwitz and Fiessler [11] developed an iterative procedure based on normal approximations to non-normal distributions at the so-called design point. Beginning with the resistance, $R$, let $F_{R}$ be the cumulative distribution function (CDF) and $f_{R}$ the probability density function (PDF) for $R$. The initial value for $R$ at the design point is guessed as $R^{*}$. Next, $F_{R}$ is approximated by a normal distribution, $F_{R^{\prime}}$, such that

$$
F_{R^{\prime}}\left(R^{*}\right)=F_{R}\left(R^{*}\right)
$$

and

$$
f_{R^{\prime}}\left(R^{*}\right)=f_{R}\left(R^{*}\right)
$$

The standard deviation of $R^{\prime}$ is

$$
\sigma R^{\prime}=\phi\left\{\Phi^{-1}\left[F_{R}\left(R^{*}\right)\right]\right\} / f_{R}\left(R^{*}\right)
$$

where $\phi_{R}=P D F$ of the standard normal random variable and $\Phi_{R}=C D F$ of the standard normal random variable.

The mean of $R^{\prime}$ is,

$$
m_{R^{\prime}}=R^{*}-\sigma_{R^{\prime}} \Phi^{-1}\left[F_{R}\left(R^{*}\right)\right] .
$$

The same procedure, described by Eq. 6-9, is carried out for all random variables in the limit state function (in this case, $Q)$.

Reliability Index $\beta$ is then computed by:

$$
\beta=\left(m_{R^{\prime}}-m_{Q^{\prime}}\right) /\left(\sigma_{R^{\prime}}^{2}+\sigma_{Q^{\prime}}^{2}\right)^{1 / 2} .
$$

A new design point value is then calculated:

$$
R^{*}=m_{R^{\prime}}-\beta \sigma_{R^{\prime}}^{2} /\left(\sigma_{R^{\prime}}^{2}+\sigma_{Q^{\prime}}^{2}\right)^{1 / 2} .
$$

The second iteration then begins; the approximating normal distributions are found for $F_{R}$ and $F_{Q}$ at the new design point. The reliability index is calculated using Eq. 10, and the next design point is found from Eq. 11. Calculations are continued until $R^{*}$ does not change in consecutive iterations. The procedure has been programmed and calculations can be carried out by computer.

\section{System reliability model for girder bridges}

Traditional design of structures is based on design of individual components such as beams, columns, tensions members, and/or connections (bolts, welds). The design codes specify nominal values of loads to be resisted by each component, and the objective of the design is to determine the required value of nominal resistance with predetermined safety factors. The load carrying capacity (resistance) of a component is expressed in terms of materials (grades and types) and dimensions (geometry). All structural components must satisfy the basic code requirement, i.e. the load effect cannot exceed the resistance. On the other hand, in most cases, component-based design is conservative because of redundancy and ductility. When the load in a critical component approaches the ultimate value, other components can take additional loads and prevent a failure. However, the quantification of this load sharing requires a special approach using the system reliability models.

A considerable effort was directed on the development of the reliability analysis procedures for structural components. The formulation of the limit state function for a structural system is much more difficult than for a component. In this paper, the reliability analysis is performed for the whole bridge. The load and resistance models, and the limit state functions are defined as follows.

The basic load combination include dead load and live load (static and dynamic). Live load is represented in form of trucks. It was observed that the axle configuration is not important, therefore, two trucks are selected: a 3-axle vehicle (denoted by $S$ ) and a 5 -axle vehicle (denoted by $T$ ), as shown in Fig. 1. It is assumed that the axle spacing and load distribution factors per axle are constants, but the gross vehicle weight (GVW) is a random variable. The transverse position of the truck within the roadway (curb distance) is also a random variable. An example of the probability density functions (PDF) of the curb distance are shown in Fig. 2, for two traffic lanes. Each PDF represents a curb distance for a line of wheels, spaced

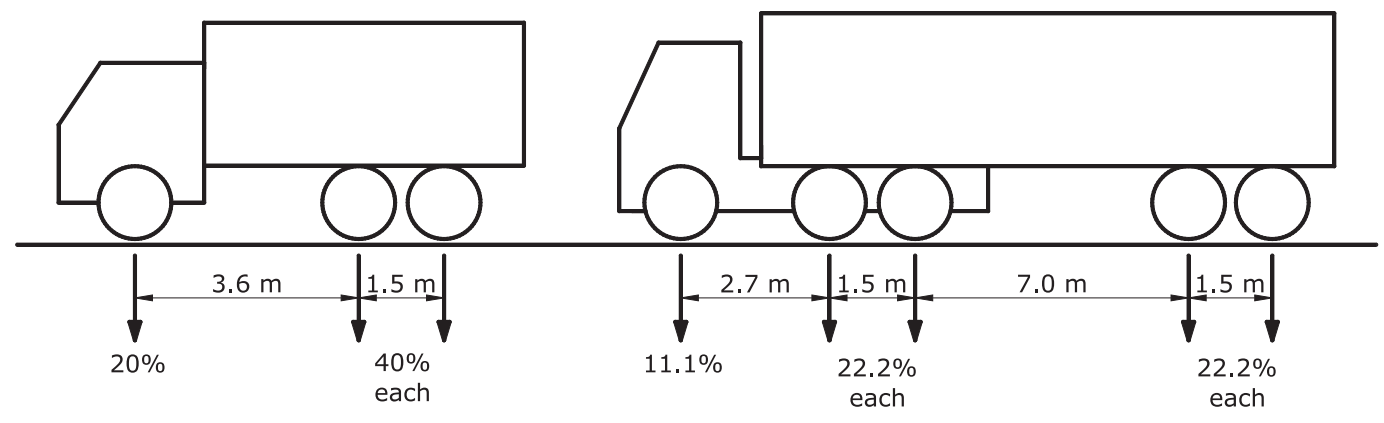

Fig. 1. Truck configurations considered in the project 


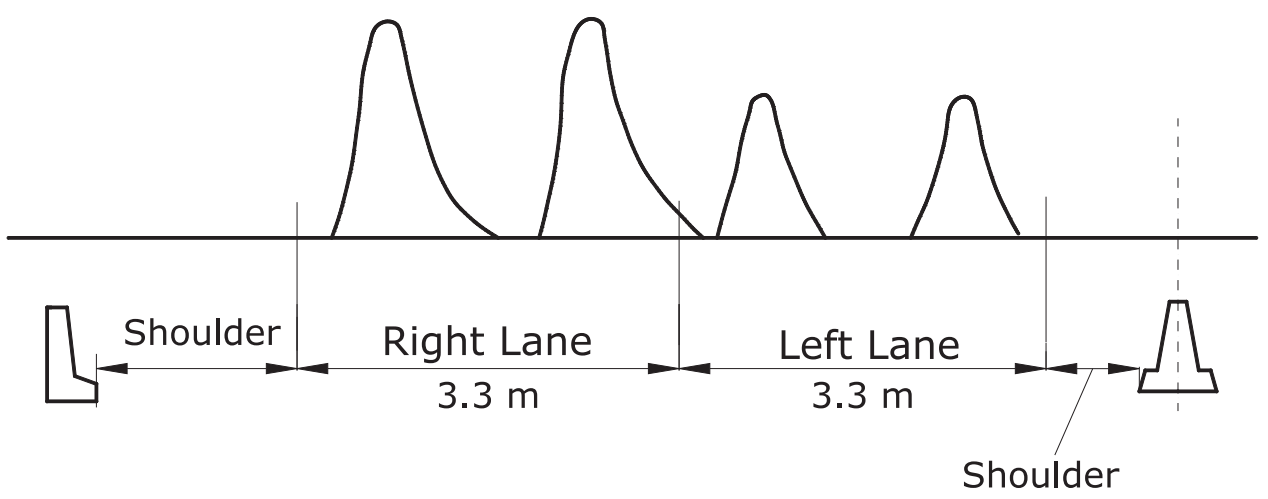

Fig. 2. Example of the Probability Density Functions (PDF) of the Curb Distance. Each PDF Represents a Line of Truck Wheels

\begin{tabular}{|c|c|c|c|}
\hline \multicolumn{2}{|c|}{ One Lane Loaded } & \multicolumn{2}{|c|}{ Two Lanes Loaded } \\
\hline Truck Placement & $\begin{array}{l}\text { Probability of } \\
\text { Occurrence }\end{array}$ & Truck Placement & $\begin{array}{l}\text { Probability of } \\
\text { Occurrence }\end{array}$ \\
\hline $\begin{array}{l}\mathrm{S} \\
-=\end{array}$ & 0.133 & $\leftarrow$\begin{tabular}{c|}
$S$ \\
$T$
\end{tabular} & 0.2 \\
\hline$\overline{\bar{T}}$ & 0.533 & $\leftarrow$\begin{tabular}{c|}
$T$ \\
$S$
\end{tabular} & 0.3 \\
\hline$\leftarrow \frac{\mathrm{s}}{\mathrm{s}}$ & 0.067 & \begin{tabular}{|c|} 
s \\
s \\
s
\end{tabular} & 0.1 \\
\hline$\leftarrow-\frac{T}{\mathrm{~T}}$ & 0.267 & \begin{tabular}{|c|}
$\mathrm{T}$ \\
$\mathrm{T}$ \\
$\mathrm{T}$ \\
\end{tabular} & 0.4 \\
\hline
\end{tabular}

Fig. 3. Considered Truck Positions and Probabilities of Occurrence

at $1.8 \mathrm{~m}$ for a truck. Various possible load cases and probabilities of occurrence are shown in Fig. 3, including simultaneous presence with two trucks in the same lane, and side-by-side.

Bridge resistance is determined for each transverse position of the truck, in terms of the truck weight. Material and component parameters of the bridge are generated using Monte Carlo technique. A finite element method (FEM) is used to calculate the strain/stress and deflections. Failure is defined as an excessive deflection. The gross vehicle weight is gradually increased until the deflection exceeds the acceptable level. The resulting GVW is considered as the system resistance, corresponding to the given curb distance. GVW is a random variable, with the statistical parameters established from the weigh-inmotion measurements.

The reliability index can be calculated for each value of curb distance. Then, the system reliability index for the bridge can be determined as the weighted average.

\section{Bridge load model}

Bridge dead load and live load (truck traffic) are the two load categories considered in this study. The load models used are based on those developed for the calibration of the AASHTO LRFD Code (2004) [5] for comparison consistency [12]. The basic statistical parameters considered are bias factor $\lambda$ (ratio of mean to nominal value) and coefficient of variation $V$.

Dead load items included are the weight of the girders, deck slab, wearing surface, barriers, sidewalks, and diaphragms, when applicable. The bias factor $\lambda=1.03$ and $V=0.08$ for factory-made components (girders, diaphragms), $\lambda=1.05$ and $V=0.10$ for cast-in-place components (deck, barriers, sidewalks), and asphalt wearing surface is taken to have a mean value of $90 \mathrm{~mm}$ with $V=0.25$.

Live load parameters are based on actual load data from a survey of heavily-loaded trucks on Michigan highways. This model assumes that every 15th truck on the 
bridge is accompanied by another truck side-by-side. It further assumes that with every 10th simultaneous occurrence (trucks side-by-side), the truck weights are partially correlated $(\rho=0.5)$, and every 30th occurrence the truck weights are fully correlated $(\rho=1.0)$. Moreover, with regard to multiple presence (multiple trucks in a single lane), every 50th truck is followed by another truck with distance between trucks from 4.5 and $30 \mathrm{~m}$; every 150th truck is followed by a partially correlated truck (with regard to weight); and every 500th truck is followed by a fully correlated truck. The results of the simulations, as pertinent to this study, are as follows: for the singlelane loaded case, bias factor $\lambda$ (ratio of actual moment to AASHTO LRFD HL-93 design moment) for a single truck varies from 1.3 for the shortest span (10m) to 1.2 for longer spans $(50 \mathrm{~m})$, while coefficient of variation $V$ is 0.11 for all spans. For the two-lanes loaded case, $\lambda$ for each truck varies from 1.2 at $10 \mathrm{~m}$ to 1.0 at $50 \mathrm{~m}$ (note $\lambda$ for the total moment on the bridge would then be equivalent to $1.2 \times 2$ trucks $=2.4$ and $1.0 \times 2=2.0$ ), while $V$ for each truck varies from 0.14 at $10 \mathrm{~m}$ to 0.18 at $50 \mathrm{~m}$.

The variation in transverse traffic position can be based on a survey of the lateral position of vehicles on interstate highways in southeast Michigan. The density function was approximated by a lognormal distribution with a coefficient of variation of 0.33 . For a standard $3.63 \mathrm{~m}$ wide lane, the mean value is equal to $0.91 \mathrm{~m}$, measured from the edge of the lane to the centerline of the outermost vehicle wheel (this corresponds to a typical $1.82 \mathrm{~m}$ axle width truck to be centered in the lane).

Dynamic load depends on roughness of the surface, dynamic properties of the bridge, and suspension system of the vehicle. Dynamic load factor is defined as the ratio of dynamic strain (or deflection) and static strain (deflection). Field tests conducted by the University of Michigan revealed a dynamic load factor of less than 0.10 for two heavily loaded trucks traveling side-by-side over various bridges $[13,14]$. Based on these results, the mean dynamic load factor is conservatively taken as 0.10 while the coefficient of variation is 0.80 .

\section{Resistance model}

The statistical parameters of the load carrying capacity (resistance) of components can be based on the previous research [12]. The basic parameters are summarized in Table 1. Laboratory results and field testing of actual bridges indicate that the traditional analysis models used for design do not accurately predict structural behaviour. One of the most significant discrepancies in behaviour can be seen in the prediction of ultimate capacity. Although limited data exists, actual girder bridge ultimate capacities have been measured from approximately 1.4 to 3.0 times the AASHTO Code-predicted values. For comparison, the Code value is determined by computing the capacity of a single girder multiplied by the number of girders on the bridge.
Table 1

Statistical Parameters of Component Resistance

\begin{tabular}{lcc}
\hline Type of Structure & $\lambda$ & $V$ \\
\hline $\begin{array}{l}\text { Non-composite steel girders } \\
\text { Moment }\end{array}$ & 1.12 & 0.10 \\
$\quad$ Shear & 1.14 & 0.105 \\
Composite steel girders & & \\
$\quad$ Moment & 1.12 & 0.10 \\
$\quad$ Shear & 1.140. & 105 \\
Reinforced concrete T-beams & & \\
$\quad$ Moment & 1.14 & 0.13 \\
$\quad$ Shear & 1.20 & 0.155 \\
Prestressed concrete girders & & \\
$\quad$ Moment & 1.05 & 0.075 \\
$\quad$ Shear & 1.15 & 0.14 \\
\hline
\end{tabular}

Discrepancies between actual and predicted behaviour exist primarily because current models do not account for important features of actual bridges which significantly affect load distribution and structural capacity. Although there are many such features, among the most important are the presence of secondary elements such as diaphragms, barriers, and sidewalks. Although the limited experimental data that exists seems to indicate that these elements may perform favorably, even until ultimate capacity, they cannot be relied upon in general to act as structural components, as they were not designed for this purpose. However, the potential benefits of including these elements as structural members may be significant, as indicated above.

In the present study, a system reliability model is developed for a bridge with steel girders composite with a reinforced concrete deck slab. Conservatively, the effects of secondary elements (barrier and parapet) are neglected. The bridge resistance is considered in terms of a truck (the same one as considered for the live load model). The statistical parameters of resistance are determined by Monte Carlo simulations.

The mechanical properties of the girders and concrete deck slab are generated for each Monte Carlo run. Resistance is calculated for each transverse position of the truck. The truck weight is gradually increased until the deflection limit is exceeded. Resistance is equal to the maximum truck weight. The analysis is repeated to determine the mean maximum truck weight and its coefficient of variation. Then, the simulations are repeated for other transverse truck positions.

\section{Reliability analysis for selected bridges}

The reliability analysis was performed for a representative group of composite steel girder bridges. Four span lengths were considered: $12 \mathrm{~m}, 18 \mathrm{~m}, 24 \mathrm{~m}$ and $30 \mathrm{~m}$, and three girder spacings: $1.8 \mathrm{~m}, 2.5 \mathrm{~m}$ and $3.0 \mathrm{~m}$. 


\section{A. S. Nowak}

Live load was applied in form of trucks shown in Fig. 1. The load-deflection curve were determined using a nonlinear FEM program. A typical load-deflection curve for the span of $18 \mathrm{~m}$ and girder spacing of $2.5 \mathrm{~m}$ is shown in Fig. 4 for two considered trucks. The results for three different transverse positions of a 3 -axle truck on a $12 \mathrm{~m}$ span are shown in Fig. 5. Case 3 corresponds to truck being in the center, and Case 1 closer to the curb.

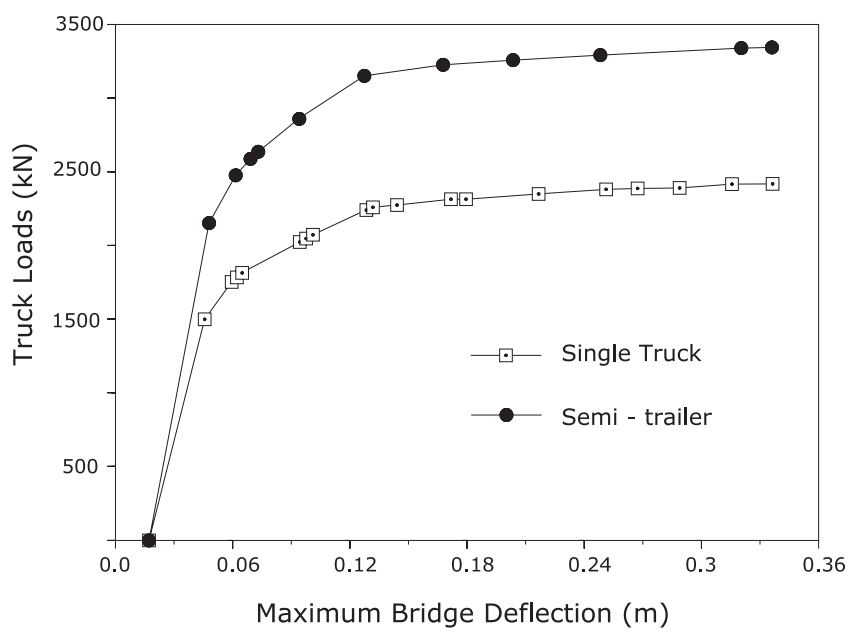

Fig. 4. Load-Deflection Curves for Two Considered Trucks, Span $=18 \mathrm{~m}$ and Girder Spacing $=2.5 \mathrm{~m}$

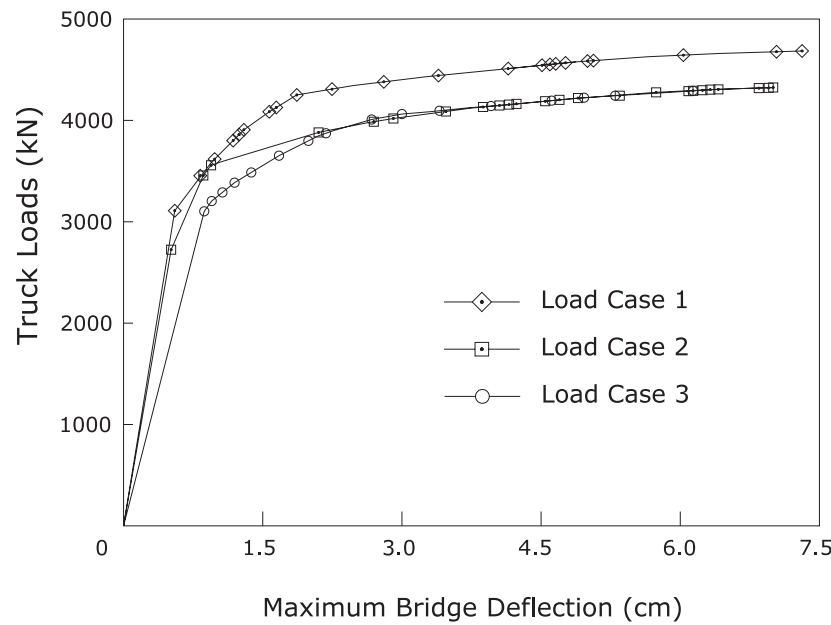

Fig. 5. Load-Deflection Curves for Different Trucks Positions, Single Tandem, Span $=12 \mathrm{~m}$ and Girder Spacing $=1.8 \mathrm{~m}$

Reliability indices were calculated for individual girders following the procedure used in calibration of the AASHTO LRFD Code [12]. It was assumed that live load distribution factors specified in the design code are applicable (linear load distribution). The analysis was performed for a wide spectrum of girder resistance values (load carrying capacity), resulting in the reliability indices from 0.5 through over 6.0 .

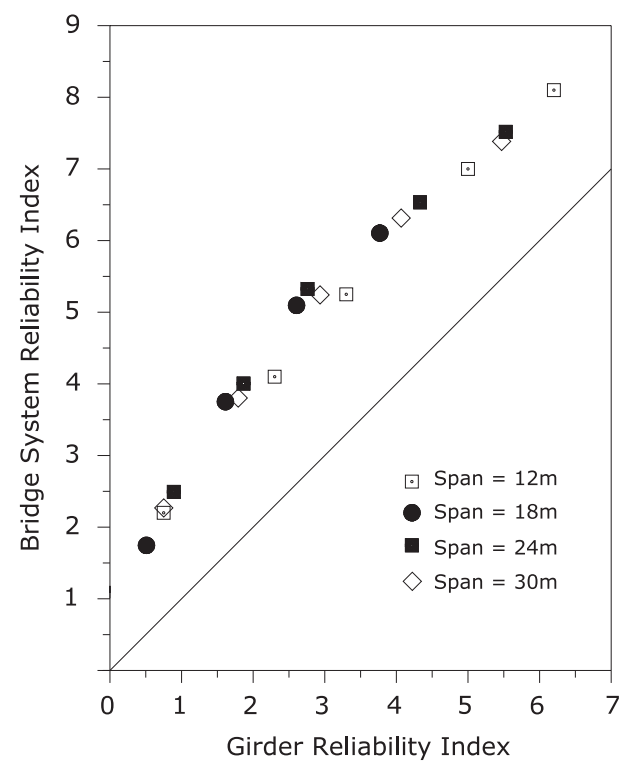

Fig. 6. System Reliability Index vs. Girder Reliability Index for Different Spans

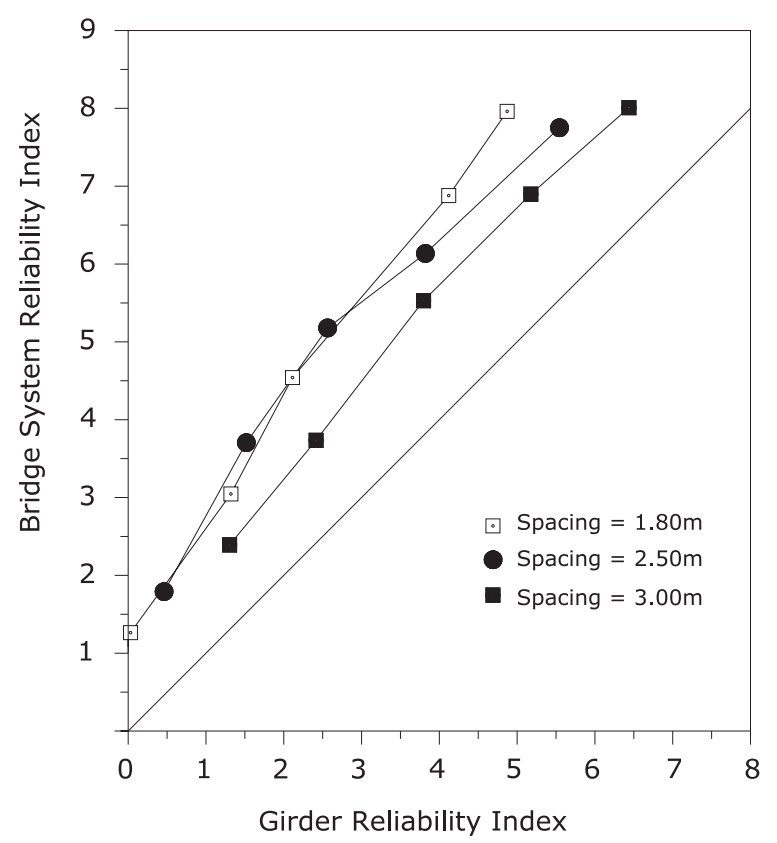

Fig. 7. System Reliability Index vs. Girder Reliability Index for Different Girder Spacings, Span $=18 \mathrm{~m}$

For each girder reliability index, the corresponding system reliability index was calculated. The results are shown in Fig. 6, for four considered spans. In Fig. 7, the girder reliability indices are plotted vs. system reliability indices for three considered girder spacings.

An important consideration in the system reliability analysis is degree of correlation between the components. There is little data available to provide a basis for statistical parameters. Therefore, the reliability analysis was carried out for two extreme cases: no correlation, with the coefficient of correlation, $\rho=0$, and full correlation, 
with the coefficient of correlation, $\rho=1$. For the span of $18 \mathrm{~m}$ and girder spacing of $2.5 \mathrm{~m}$, the results are shown in Fig. 8.

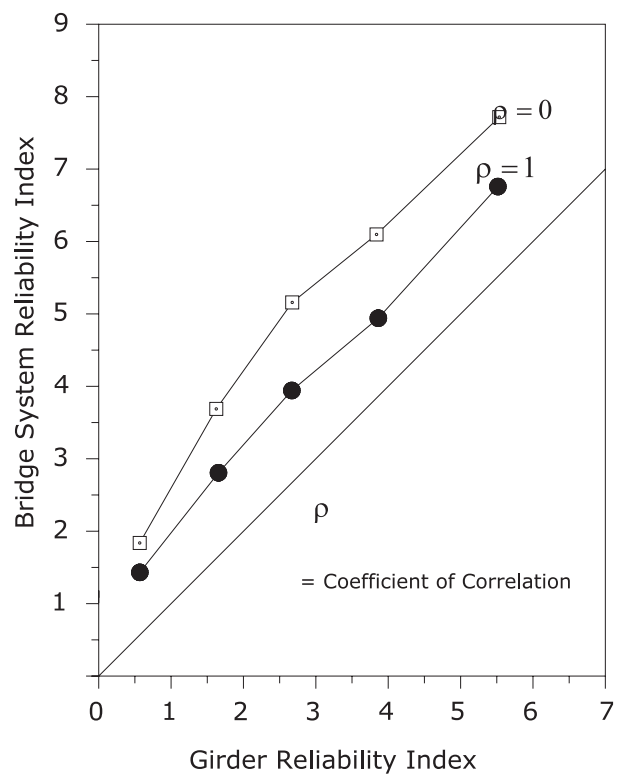

Fig. 8. System Reliability Index vs. Girder Reliability Index for No Correlation and Full Correlation between Girder Resistances, Span $=18 \mathrm{~m}$, Girder Spacing $=2.5 \mathrm{~m}$

\section{Sensitivity analysis}

Structural reliability depends on a number of load and resistance parameters. These parameters are represented by the statistical parameters such as the mean, bias factor and coefficient of variation. However, some statistics can be based on insufficient data base and/or subjective judgment. Therefore, it is important to identify the most sensitive parameters in the reliability analysis. These parameters can then be considered as the prime target in the effort to control probability of failure.

Using the developed system reliability procedure, the sensitivity functions were developed for an individual composite steel girder and for the whole bridge. Each sensitivity function represents the relationship between a parameter and reliability index. The results of the computations performed for a composite steel bridge girder are plotted in Fig. 9. Various values of the bias factor (mean value) are considered for the considered parameter, from the actual value required by the code, up to value that is over $40 \%$ different, either larger (loads) or smaller (strength). The sensitivity functions for the whole composite steel girder bridge are shown in Fig. 10.

The results clearly indicate that the most important parameters are related to resistance, in particular plastic section modulus and yield stress of the steel beam. On the other hand, the least sensitive parameters are compressive strength of concrete and effective width of the slab. Dead load estimation is also unimportant.

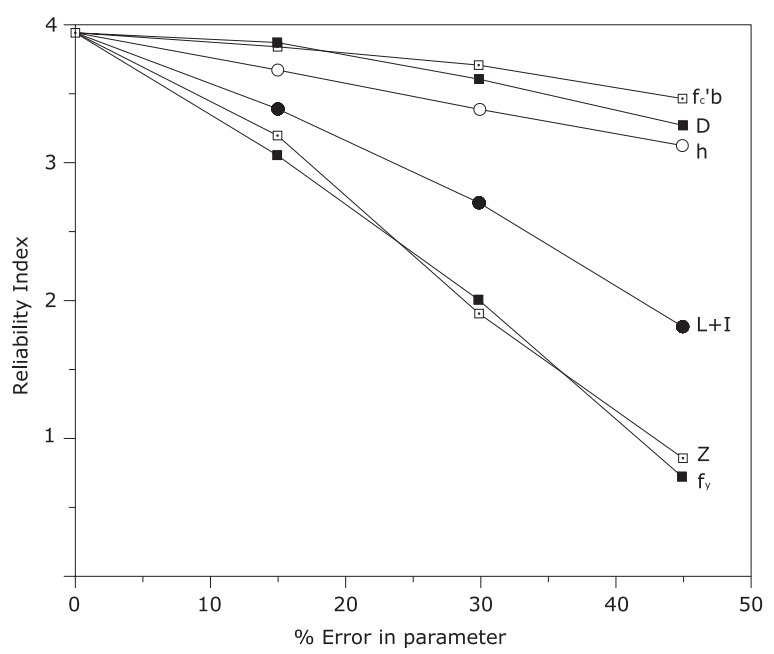

Fig. 9. Sensitivity Functions for a Composite Steel Girder; $f_{c}^{\prime}=$ Compressive Strength of Concrete, $b=$ effective width of the concrete slab, $h=$ effective depth of the slab, $Z=$ plastic section modulus of steel beam, $f_{y}=$ yield stress of steel, $D=$ dead load moment, $L=$ live load moment, $I=$ dynamic load moment

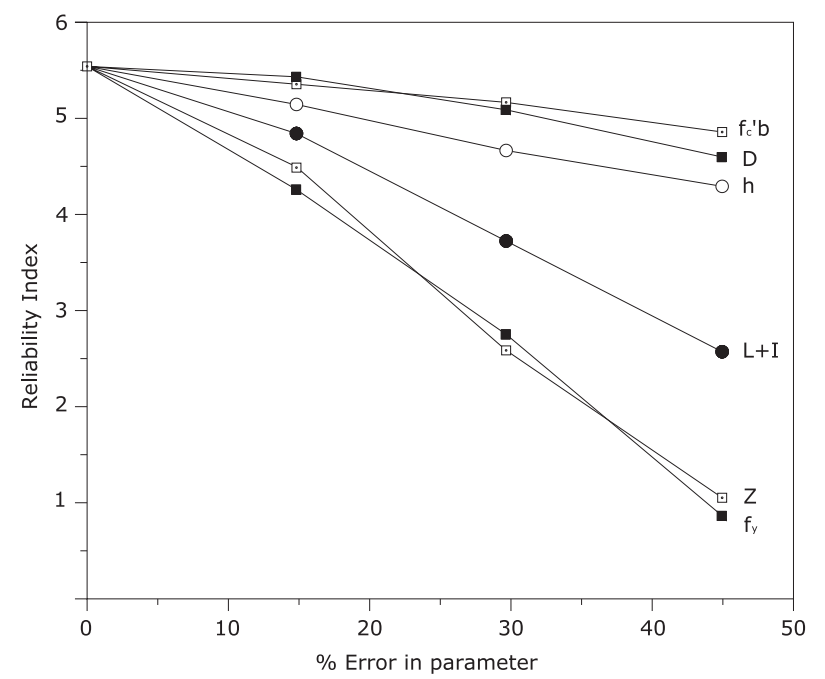

Fig. 10. Sensitivity Functions for a Composite Steel Girder Bridge; $f_{c}^{\prime}=$ Compressive Strength of Concrete, $b=$ effective width of the concrete slab, $h=$ effective depth of the slab, $Z=$ plastic section modulus of steel beam, $f_{y}=$ yield stress of steel, $D=$ dead load moment, $L=$ live load moment, $I=$ dynamic load moment

\section{Conclusions}

Reliability can be considered as a rational measure of structural performance. The reliability analysis methods were developed and applied mostly for structural components (elements), rather than structural systems. The objective of this paper is to present a procedure for calculation of the reliability index for girder bridges. The analysis demonstrated on a representative sample of composite steel girder bridges. The calculated reliability indices are compared with reliability indices determined for individual girders (elements). 
It is observed, that the ratio of $\beta_{\text {system }} / \beta_{\text {girder }}$ decreases with increasing $\beta_{\text {girder }}$. It is about 2 for $\beta_{\text {girder }}=$ 1 , and 1.3 for $\beta_{\text {girder }}=6$.

It was also found that the coefficient of correlation, $\rho$, can decrease $\beta_{\text {system }}$ by $15-30 \%$. There is a need for more data on the actual conditions.

Sensitivity analysis can be used as an efficient tool to identify the most important load and resistance parameters. The analysis can be performed for the components (elements) and whole structural systems.

Acknowledgements. Presented research was partially sponsored by grants from the National Science Foundation which is gratefully acknowledged. Thanks are due to current and former doctoral students at the University of Michigan: Artur Czarnecki, Chris Eamon, Junsik Eom, Sangjin Kim, Hani Nassif, Vijay Saraf, Sami Tabsh, Hasan Tantawi, Ahmed Yamani and Jian-Hua Zhou.

\section{REFERENCES}

[1] G. Konig and A. S. Nowak, (ed.), Bridge Rehabilitation, Ernst \& Sohn, Berlin, Germany, 1992.

[2] V. Saraf and A. S. Nowak A.S., "Proof load testing of deteriorated steel girder bridges", ASCE Journal of Bridge Engineering 3(2), 82-89 (May 1998).

[3] V. Saraf, A. F. Sokolik and A. S. Nowak, "Proof load testing of highway bridges", Transportation Research Record 1541, 51-57 (1997).

[4] M. Ghosn and F. Moses, "Redundancy in highway bridge superstructures" in: NCHRP Report 406. Transportation Research Board, Washington, D.C., 1998.

[5] AASHTO LRFD Bridge Design Specifications, Washington, D.C., 2004 .

[6] CHBDC, Canadian Highway Bridge Design Code, Canadian Standard Association, Toronto, 2003.

[7] ENV 1991-3 Eurocode 1: Basis of Design and Actions on Structures. Part 3: Traffic Loads on Bridges. Final draft - August 1994.

[8] C. D. Eamon and A. S. Nowak, "Effects of edge-stiffening elements and diaphragms on bridge resistance and load distribution", ASCE Journal of Bridge Engineering 7(5), 258-266 (September/October 2002).

[9] A. S. Nowak and M. Kaszynska, "Target safety levels for design and evaluation of bridges", Transactions of Joining and Welding Research Institute 32(1), 189-196 (2003).

[10] A. S. Nowak and K. R. Collins, Reliability of Structures, pp. 184-195; 302-311, McGraw Hill, Boston, 2000.

[11] R. Rackwitz and B. Fiessler, "Structural reliability under combined random load sequences", Computer and Structures 9, 489-494 (1978).

[12] A. S. Nowak, Calibration of LRFD Bridge Design Code, NCHRP Report 368. Washington, D.C., 1999.

[13] S.-J. Kim and A. S. Nowak, "Load distribution and impact factors for I-girder bridges", ASCE Journal of Bridge Engineering 2(3), 97-104 (August 1997).

[14] J. Eom and A. S. Nowak, "Live load distribution for steel girder bridges", ASCE Journal of Bridge Engineering 6(6), 489-497 (2001). 